\title{
Integrating PMBOK Standards, Lean and Agile Methods in Project Management Activities
}

\author{
Mohamed-Larbi Rebaiaia \\ Department of Mechanical Engineering \\ Faculty of Science and Engineering \\ Laval University, Quebec (Qc), Canada
}

\author{
Darli Rodrigues Vieira \\ Department of Management Sciences \\ University of Quebec at Trois-Rivières \\ Trois-Rivières, Quebec $(\mathrm{Qc})$, Canada
}

\begin{abstract}
Nowadays, populations are concentrated in large cities exceeding millions of peoples; the need for massive infrastructure constructions and services becomes the priority for governments and local municipality institutions. However, the realization of such projects still problematic and conventional techniques quickly become inadequate. Project Management Body of Knowledge (PMBOK) recommendations, Lean and Agile methods have been proposed to facilitate the effective project deployment and organization for minimizing resources, costs, durations and risks. The purpose of this paper is to compare the effect of PMBOK standard, Lean and Agile methods on the project management processes to make tangible profits. It is intended to propose some solutions for organizing the project execution more effectively. The results of this presentation show that PMBOK, Lean and Agile strategies are complimentary and can improve the visibility when performing complex projects.
\end{abstract}

\section{Keywords}

Project management, PMBOK, Lean management, Agile methods, Composition.

\section{INTRODUCTION}

It is evident that man has always realized large-scale projects regarding to the dozens of gigantic and fabulous works that have been accomplished by the Greek, Roman, Chinese, Pharaohs, Aztec, Mayan and Muslim civilizations (e.g. in Figure 1). Unfortunately, the realization of such projects has seen much bloodshed and a lot of time and money spent. Nowadays, man has been modernized and only aspect that interests him is how it can earn the more possible of money while spending the least possible time without risks. He is aware that one of the ways that lead to successes depends more than ever on the ability of the project team to select appropriate resources (e.g. capital, equipment, people, and so forth), techniques and methods such that to meet the needs of customers by creating projects and especially to well define their scope (tangible objectives, goals, sub-phases, tasks, etc.). As organizations perform work, work involves projects. Generally, projects share many common characteristics. They are for example performed by people or programmed machines, constrained by limited resources, planned, executed and controlled. Defining exactly what mean a project is hazardous, but it'll settle for definitions not only academic but also standardized and described terminology are applicable to projects most of time. There is a widespread consensus about their value and their usefulness. Rosenau and Githens [22] define a project as a kind of work that is temporary, unique, and progressively elaborated. A similar definition is published in PMBOK $[3,5]$ and states that a project is temporary endeavor undertaking to create a unique product or service. Temporary means that every project has a definite beginning and a definite end. A project is usually divided into phases, each one leading to the provision of deliverables [5].

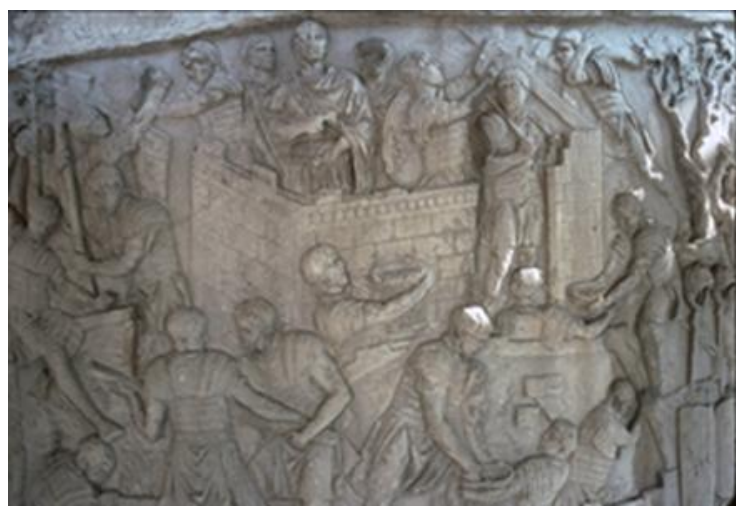

Figure 1. Roman soldiers building a fortress, Trajan's Column 113 AD (http://en.wikipedia.org/wiki/ Project_management)

Todays, classical project management approaches have proven to be inefficient for managing modern large infrastructure projects in both public and private sectors. Effectively, several known world-wide projects exceeded time and budget originally anticipated. Burj Khalifa (Figure 2) inaugurated in Jan. 2010 and Khalifa Port (Dubai, Emirates Arab United) are among recent examples who failed to be delivered in the schedule delays causing a major crisis that provoked the bankruptcy of hundreds or even thousands of small enterprises and banks. Note that, the total budget for the Burj Khalifa is about 1.5 billion U.S $\$$ and the urban complex of all downtown Burj Khalifa rises to about 20 billion U.S \$. Several studies have demonstrated that the problem happened because of a lack of coordination and alignment of interests between the project owner and the Project Management Consultant (PMC) companies [1].

Recent examples of large infrastructure projects show that the delays can run from months into years, and costs can be up to four times as much as estimated [2]. Many of the largest projects have encountered financial distress in one form or another (e.g., EuroTunnel, EuroDisney, Enron's Dabhol Power Plant, Iridium, Globalstar, Global Crossing - the Atlantic Crossing and Pacific Crossing cables, Canary Wharf, etc.). Generally, the problem is due to a lack of understanding between the different partners involved in the project and not at all a problem of miscalculation of the budget and risks estimation. A question that dominates the debates is "what" are the necessary tools and behaviours that every partner can take to facilitate the success of a large project. It is intended that one solution could focusing on three areas: defining the right management structure or operating model, designing the PMC contract to provide effective incentives, and developing adequate internal capabilities to monitoring projects [1]. Properly structuring the relationship between the owner and the PMC, with the right operating model and the right kind of contract can increase the likelihood of project success and is 
known to be a good alternative. These facts have been demonstrated not sufficient, but they can be fructified using PLM standards and recommendations. PMBOK of the Project Management Institute (PMI) could be such a solution. PMBOK directives are available as a book and links of publishers can be found at [3].

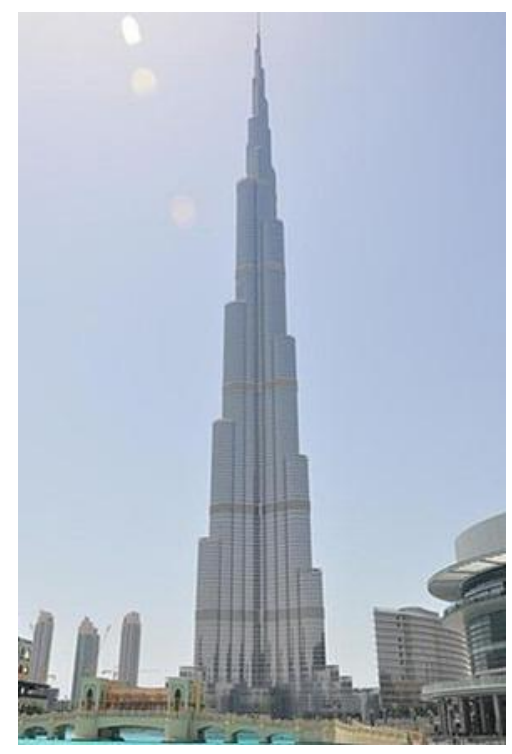

Figure 2. Burj Khalifa Tower (http://fr.wikipedia.org/)

In front of big challenges for conducting large projects, several project companies are moving slowly toward the exploitation of new tools and methodologies providing relatively clear windows into project management process by which managers make important financing and structuring decisions associated with large projects. They reflect conscious attempts to increase value and manage risk. As a result, there are significant opportunities to improve the way managers make major investment decisions, and then structure and finance them [2].

The purpose of this paper is to try to demonstrate that the combination effect of PMBOK recommendations, Lean and Agile methods could improve the visibility of the project management processes for making tangible profits in term of organization, dynamic cooperation, delays and resources optimization.

The following section describes project lifecycle as it appeared in the literature. Section 3, gives an overview of PMBOK standard Section 4 , section 5 and section 6 present respectively Agile, Lean and PMBOK-Lean-Agile framework as a new paradigm associating PMBOK guidelines, Agile and Lean methods. Section 7 closes the presentation..

\section{LIFECYCLE PROJECT MANAGE- MENT}

Project management is known as the framework for realizing the objectives of a project or a program of projects. Project management (context and processes) is the application of knowledge, skill, tools, and techniques to project activities in order to meet or exceed stakeholder needs and expectations. It is generated from the application of a succession of phases commonly called PLM. Virtually, a PLM is no more than : initiating the project, planning the work, working the plan, making changes as necessary and close out the project. Phases could also be presented according to Figure 3. Unfortunately the problem is more complicated to be explained with such simple terms. Why? Because considerable funds are committed to the success of the project, namely, a lot of money is invested; time and men efforts are being made before and after the early achievements, and especially the risk of a miscalculation of deployed resources, calculus errors and customer's dissatisfactions. However all these constraints can occur when the project evaluation (requirements specification) phase does not reflect careful ways of what real means that must be used for the project ends in the best conditions.

Formally, PLM is defined as the process of managing the entire lifecycle of a product or a project from its conception, through design and manufacture, to service and disposal. PLM integrates people, data, processes and business systems and allows companies to manage their entire lifecycle of products quality, cost and risk effectively and shorting of time to market can be achieved. PLM provides an efficient process that lets partners and suppliers to share information and data with each other's. It is the sum organizational and strategic measures for the entire lifecycle of a product.

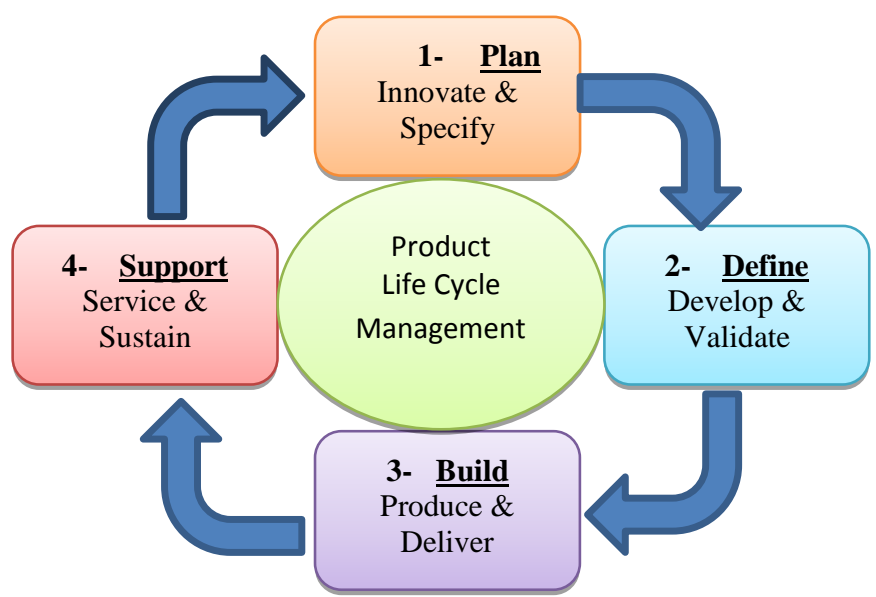

Figure 3. Commandments of PLM process

The problem with PLM is that the transition from one phase to another occurs only if the deliverables of the subsequent phase are controlled, tested and validated once and only once the deficiencies have been removed. Therefore it should be noted that in PLM phases it is too rigid to allow returning back, so that if at a later phase an abnormality is detected this assumes that it cannot affect the past phases which is completely contrary to the smooth running of the project. It can also be realized that the customer will remain just a passive observer with no right to intervene because all his solicitations were made at the beginning of the project, during the requirements specification phase. In addition to the problem of communication between customers and managers and late suppression of the risk factors, the model uses and produces voluminous documentation which sometimes does not reflect the reality of the project implementation since it happens to be rather theoretical and conceptual.

Finally, we can note that PLM brings benefits in four main areas [http://www.techdrummer.com/], they are as follows:

- Financial Performance - PLM should lead to increased revenue from earlier market introduction of products, and to reduced product development costs.

- Time Reduction - PLM should reduce project overrun time, and reduce engineering change time.

- Quality Improvement - PLM should help, for example, to reduce manufacturing process defects, reduce the number of returns and recalls, and reduce the number of customer complaints. 
- Business Improvement - PLM can lead to an increase in the innovation rate, increase the part reuse factor, increase product traceability, and ensure $100 \%$ configuration conformity.

In this context of rigid methods, the best job is to propose operational ways to give more flexibility to projects to be adapted to different solicitations, especially improving and enabling customers to propose the necessary adjustments from their point of view in such a way to give them more satisfaction, more consulting time and more collaboration, which necessarily increases the quality of the project realization while minimizing risks. Within this framework of flexibility, PMBOK guidelines, Lean and Agile methods are best solutions that can be adapted very well to this new way of managing projects and avoiding all communication problems. The second point which will be debated is that we point our efforts for minimizing the documents support for being used during the project execution and to use exactly what quantity and what kind of resource's the project needs. In this case we use accurately the Lean thinking for avoiding everything that is not useful to the smooth running of the project and thus eliminate waste.

In the following a standard and two methods will be presented and explained. The main goal of doing that is to show that combining some directives associated to some methods could improve clearly the visibility of a project and thus details the role of each one of partners. First of all, we introduce PMBOK as a standard for structuring the project management processes. After that, the combination of Lean and Agile methods will be used for reinforcing PMBOK.

\section{OVERVIEW OF PMBOX STANDARD}

PMBOK is a guide to project management designed and built by the PMI $[3,5]$. PMBOK outlines quality management principles and practices as they relate to the management of projects. It provides the guidance on quality issues that impact projects. It is applicable to projects of varying complexity, size and length. The guidelines can be applied to projects managed by an individual or by a team or for a portfolio of projects. The guide therefore aims rather to stabilize and structure the knowledge needed to drive a current project in the best conditions. The first version of this guide was published in 1987, and Version 4 is the current version (2009) [11]. Since version 3 of 2004, the PMBOK is IEEE standard 1490-2003. PMBOK is also a process oriented and each process is described in terms of inputs (data, documents ...), outputs (data, documents, products ....) and activities (input processing, techniques, tools ...).

3.1 PMBOK recognizes five basic process groups (Initiating, Planning, Executing, Monitoring and controlling, and Closing) and nine knowledge areas typical of almost all projects. They are: Project Integration, Management, Scope Management, Time Management, Cost Management, Quality Management, Human Resource Management, Communications Management, Risk Management and Procurement Management.

3.2 Each knowledge area contains some or all of the project management processes, for example, Project Procurement Management.

Much of PMBOK is unique to project management and in the area of quality management PMBOK recommendations are clear and easy to follow. It tries to ensure that the project is managed in a quality way, following established quality policy and standards for the organization. PMBOK gives a great importance to customers and it does a better job of describing the need to identify the customer, determine and manage their requirements. In the spirit of PMBOK a good contract doesn't always equate to a mutually beneficial supplier relationship. However, PMBOK discusses the need to communicate to all stakeholders, including manager, about the project's progress. The PMBOK outlines the process for identifying and acquiring resources for the project. It includes a description of how to review the resource requirements and emphasizes the contract itself, rather than the process of acquiring and managing the resources.

\section{AGILE MEHODS}

Agile methods have become highly prevalent since a group of persons meet together in 2001 to discuss the inefficiency of existing software development methods. They came up with the agile manifesto, which describes the following four important values:

- Individuals and interactions over processes and tools;

- Working software over comprehensive documentation;

- Customer collaboration over contract negotiation;

- Responding to change over following a plan.

Twelve principles underlie the Agile Manifesto, including [14]

- Customer satisfaction by rapid delivery of useful software;

- Welcome changing requirements, even late in development;

- Working software is delivered frequently (weeks rather than months);

- Working software is the principal measure of progress;

- Sustainable development, able to maintain a constant pace;

- Close, daily co-operation between business people and developers;

- Face-to-face conversation is the best form of communication (co-location);

- Projects are built around motivated individuals, who should be trusted;

- Continuous attention to technical excellence and good design;

- Simplicity- The art of maximizing the amount of work not done is essential;

- Self-organizing teams;

- Regular adaptation to changing circumstances.

Several methods have been underlined in Agile literature including: eXtreme Programming [6], Dynamic Systems Development Method [7], Crystal Methods [8], Feature-Driven Development [9], Lean Development [10] and Adaptive Software Development [11]. These methods differ in specific techniques. They have in common several characteristics, including short iterative lifecycles, quick and frequent feedback from customers, and constant learning. Among them, Scrum and XP are by far the most widely adopted. XP for example provide tools for addressing the analysis, the development and test phases and this correspond exactly to the PLM process.

In Scrum formalism, there are three core roles named pigs and a range of ancillary roles named chickens (related to the story of The Chicken and Pigs). The core roles are those committed to the project: Product owner, Development Team and Scrum Master. Each one of them has a responsibility [24]. For example, Product Owner represents the stakeholders. The owner assures that the team delivers value to the business. The Development Team is responsible for delivering potentially shippable increments at the end of each iteration, and the Scrum Master act as a buffer between the team and any distracting influences. He assured that the Scrum is used as intended. So he is the controller and keeps the Development Team to be focused to his assigned tasks.

The Ancillary roles are for example determined by task assigned to the stakeholders (customers, vendors) and managers. 
Iteration in Scrum is called Sprint; it is the basic unit of development. A sprint last between one week and one month [25]. Figure 4 presents the lifecycle of an instance of Scrum process. For more details about Scrum, please see [24].

A numerical taxonomy of agile manufacturing strategies was developed recently by Zhang, based on a large scale questionnaire study of UK industry. The taxonomy suggested the existence of three basic types of agility strategies: quick, responsive, and proactive. The author studied the case why companies choose each type of the strategies and why and how they are implemented [12].

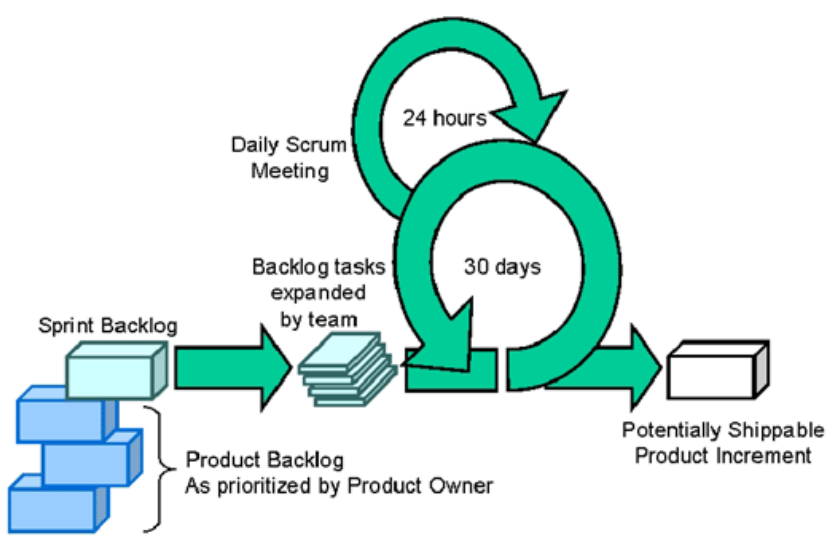

Figure 4. The lifecycle of Scrum Method

(source : www.methodsandtools.com/)

The advantage in Agile methods is, instead of building the whole product, you build the smallest possible useful part and give it to users, who tell you what is right and what is wrong. So the relation between designers and customers become an evolutionary conversation in which incremental steps of two to four weeks lead to feedback that allows requirements to be tested and adjusted (see. Figure 4). It is based on iterative and incremental development process as shown in Figure 5. Agile focuses on quality by making things like test-drivendevelopment, continuous integration, and refactoring essential pillars of the process. Quality also increases in because using a working system exposes defects right away instead of leaving them to a final testing phase. Many other aspects of Agile are beneficial and could be used for more describing the requirement of a comprehensive solution [23]. They are,

- Active user involvement is imperative;

- The team must be empowered to make decisions;

- Requirements evolve but the timescale is fixed;

- Capture requirements at a high level; lightweight and visual; • Develop small, incremental releases and iterate;

- Focus on frequent delivery of products;

- Complete each feature before moving on to the next;

- Apply the $80 / 20$ rule;

- Testing is integrated throughout the project lifecycle test early and often;

- A collaborative \& cooperative approach between all stakeholders is essential.

By definition, Agile promotes the creation of an adaptable and evolving team process - it accommodates the fact that each project is different, and processes need to fit the situation. Agile also emphasizes communication and collaboration over documentation - thus, it enables teams to move quicker by resolving things face-to-face. It also considers the customer a part of the team, thereby ensuring maximum feedback reaches the ultimate users, and allowing them in turn to change the course of the work product.

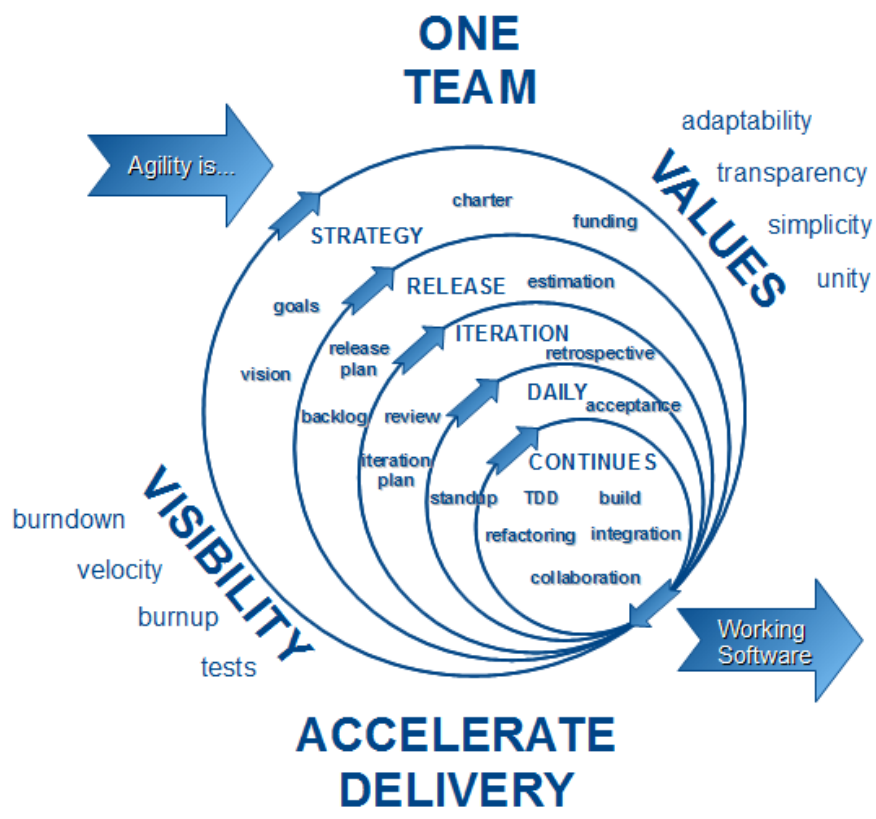

Figure 5. Development process of Agile methodology

(source: www.pathfindersolns.com/)

While agility can be seen as a mean to an end, a number of approaches have been proposed to quantify agility. Agility Index Measurements (AIM) [15] scores projects against a number of agility factors to achieve a total. The similarly named Agility Measurement Index [16] scores developments against five dimensions of a software project (duration, risk, novelty, effort, and interaction). Other techniques are based on measurable goals [17]. Another study using fuzzy mathematics [18] has suggested that project velocity can be used as a metric of agility. There are agile self-assessments to determine whether a team is using agile practices (Nokia test [19], and Karlskrona test [20]).

\section{LEAN MANAGEMENT}

Lean Management is a system of organization based on continuous improvement with a strong participation of all personnel involved in the strategy of small steps process known as the Kaizen (Kai: improvement, Zen: good) [27]. The principle objective of the Lean methodology is to improve the best process performance by exploiting the methods, techniques and practices currently available. In a Lean system, the work is broken into a set of value streams triggered by demand signals. The output of one value stream leads to others. The suppliers for materials needed are alerted through a system of just-in-time (JIT) replenishment of parts and components called Kanban [26]. The idea behind JIT is to have the supplies a company needs at the exact moment that they are needed. In order to accomplish this goal a firm must constantly be seeking ways to reduce waste and enhance value.

Lean Management involves all stakeholders to eliminate waste which reduce the efficiency and performance of a project or a production unit in that sense to eliminates operations that do not provide value to the customer. It therefore address the seven types of waste, they are named in Figure 4. 


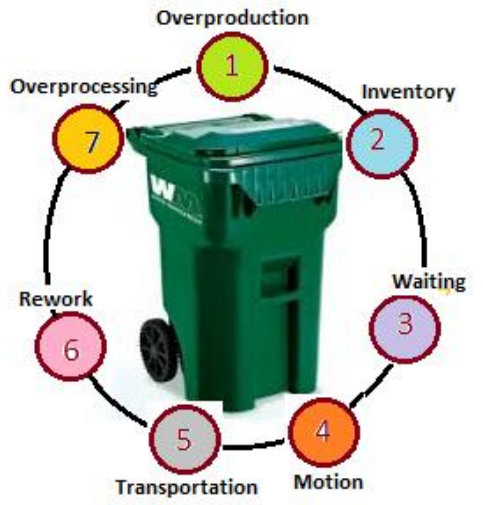

Figure 6. The 7 major wastes in Lean methods

Therefore, the Lean philosophy is "Make it better, improve it even if it is not broken, because if we do not, we cannot compete with those who do", "Better than yesterday, less than tomorrow", "Built only is needed", "Eliminate anything which does not add value", "Stop if something goes wrong", "Respect those engaged in the work", "Strives for full utilization of workers' capabilities" and "Places authority and responsibility for the work with those doing it. These are beautiful statements which if applied seriously can improve projects feasibility and capital gain.

The engine of continuous improvement is the PDCA Plan-DoCheck-Act) and TQM (Total Quality Management) also called business excellence, whose objective is to obtain a broad mobilization and involvement of the entire company to achieve perfect quality and the customers satisfaction. TQM implements all approaches of operational excellence as Six Sigma [13] and consider risk management, sustainability and staff motivation. CTQ (Critical To Quality) represents the measurable customer expectations on product and service quality. The diagram CTQ aims to decompose customers' requirements based on 3 criteria: Quality, Costs and Delays. CTQ also provides a constructive dialogue with customers to improve the product.

Some examples of tools used in lean management are:

- 5S: The first letters of five Japanese words (Seiri: dispose, Seiton: ranger, Seiso: clean, Seiketsu: order, Shitsuke: be rigorous) that aim to store, clean, and eliminate the causes of many glitches source of loss of efficacy. This is one of the first methods to implement a lean management approach. It also seeks to change the mindset of operators and managers.

- The VSM (Value Stream Mapping): Analysis of the value chain, physical flows and flow time of production (since the entry of raw materials to shipment of finished products packaged). This analysis helps identify issues and priorities for action plan implementation of Lean Management (also called Roadmap).

- Visual Management: The visual management is at the heart of Lean Management, and is based on the transparency of results in real time to improve responsiveness to identified problems. Each area or service must have its own indicators displayed on site. The significant deviations from the objectives should lead to an analysis and a corrective action plan.

Six Sigma from Motorola another well-known methodology, have been associated with Lean as business improvement methodologies [31]. Their ends goals are similar, but they focus on different side of the project. They are wholly complementary. More details are given in [13].

\section{AGILE, LEAN AND PMBOK: A NEW PLM SOLUTION}

Product innovation in a compressed time frame puts enormous pressure on companies to manage efficiently their budget, time and allocation of material and human resources. In this context, Agile and Lean are becoming widely accepted approaches in industrial, civil and software engineering. Their association is considered as a new competitive strategy concept and is claimed to be "the next wave of life-cycle process". However, how to develop an engineering strategy based around PMBOK, Agile and Lean is not fully clear and the application of a unified framework associating them is needed than ever. Typical framework will assemble strategies and program actions to be used for implementing them.

A retrospective studies show that a part of Agile community has started to look toward Lean approaches capability, in addition to Agile methods such as XP and Scrum. Others even consider Lean as just another Agile method [11]. Last research publications show that an increasing focus on Lean is viewed as being a method category in itself rather than an instance of Agile methods [28]. Researchers admit that moving from Agile to Lean or associating Agile and Lean gives more clearness to the PLM process. Some claim that Lean software development provides the theory behind Agile practices [29]. Others argue that Lean is a necessary progression for organizations planning to scale up agility from the project or team level to the organizational level, which Agile methods fail to address satisfaction [30]

From a point of view of PLM experts, Agile methodology is not a magic bullet but its combination with Lean strategies can improve the visibility, the collaboration behavior and can provide more opening to represent the lifecycle process to deal with concrete problems.

"Scrumban" for example is an association of concepts proper to Scrum (Agile) and kanban (Lean) [28]. It is believed to be especially suited for maintenance projects or projects with frequent and unexpected user stories or programming errors.

The Lean concept of Kaizen also has a strong influence on the way Agile is being practiced, filling a gap relating to continuous improvement. The evolution of Agile is primarily focused on evolving the product toward a better fit with requirements. In Agile, both the product and the requirements are refined as more is known through experience. When Kaizen is practiced in an Agile project, the participants not only suggest ways to improve the fit between the product and the requirements but also offer ways to improve the process being used, something usually not emphasized in Agile methods. From [21], "the power of Agile is that it's self-adaptive," Eckfeldt says. "It teaches software teams how to deliver value to customers and how to improve themselves using techniques like Kaizen, allowing them to deal with unique and changing constraints and environmental factors."

In practice, Agile seems to be changing for the better by adopting Lean thinking in a large way. Rally says that its customers get to market $50 \%$ faster and are $25 \%$ more productive when they employ a hybrid of Lean and Agile development methods. Given the way that Agile fits in to the Lean framework and why not to be considered a branch of Lean practice.

In PMBOK, Agile and Lean are not specifically mentioned or related to any of PMBOK items, however PMBOK tends to describe what a project manager should be managing, and not much about how to manage it. For example, some sections in PMBOK speak about how to manage scope, how to manage resources, how to manage finances, how to manage the schedule, etc. By cons, Agile and Lean methods tend to focus how should 
be done. Agile and Lean didn't at all follow specified PLM phases, which could trigger a manner for creating enrichment link for augmenting PMBOK capability as they are largely complimentary. So combining PMBOK, Agile and Lean can further enhance their usefulness.

As it was cited previously, PMBOK emphasizes 5 phases (Initiating, Planning, Executing, Monitoring and controlling, and Closing), the same successive steps are also encountered in Agile and Lean but they must be more clarified so such to be detailed at each iteration (Sprint).

Lean and more specifically Six Sigma is a quality management approach that is similar to PMBOK guidelines. They are process, customer and improvement oriented. Steve Pham, PMP, senior manager of the Denver, a management and IT consulting firm, consider both PMBOK and Six Sigma as mirror images of each other. Pham recognized that Six Sigma techniques alone would not ensure project success. Layering with a method that could help plan, execute, monitor and control the project is effectively embedded in PMBOK.

Finally, it state that both Lean and Agile focus on people, on inspecting and adapting in order to improve the work-product and efficiency in producing it. In other words, feedback is critical from people, from customers, from stakeholders, and from the product itself. They're both quality focused, and they encourage early discovery and more importantly, prevention of defects.

The area where they complement each other most is in the breadth of their world-view. Agile is usually focused very much within the software development team or organization, Lean focuses on the entire system as manufacturing in the presence of workers, partners, customers, external stakeholders as possible.

\section{CONCLUSION}

Todays with the globalization, cities around the word become gigantic trading centers. They attract more people and therefore the necessity to build adequate infrastructure to meet their daily needs become a big challenge for governments, which then lead to make massive investments. Managing those large projects will not be a simple task: Studies conducted by the Standish Group ( $3 \mathrm{w}$. standishgroup.com) show that proportion of projects that are considered success says respecting the CSC disposals (Content, Schedule, Cost) remains low, between $25 \%$ and $30 \%$. It means that three of four projects are complete or partial failures. They are dropped or succeeded after costs revaluation and hence a stretch of time is more than necessary, or simply the project is lowered with less components. As a result, project owners will continue to turn to professional program managers to help them execute projects. To reap the benefits and to increase the likelihood of success, projects management companies must to be engaged to put aside the old project management techniques to establish effective project governance and build internal capabilities to track and monitor the project's progress. Integrating in a toolkit PMBOK guidelines, Lean and Agile methodologies provide a road to excellence regarding the feasibility and create more flexibility in conducting projects realizations. In practice, few companies are able to take on these project management approaches immediately and adopt them successfully over a short period- a full transition often taking a few years. The problem is due to the fact that despite the heaviness of the old methods, they feel safer with them and very familiar with.

In this paper we have presented each one of these three methodologies and showed the good and the bad side of each one of them. We sometime explained the relation between them and how to associating them. Our aim in this presentation is to show that by using PMBOK one can provide responses to the what to do and what to don't do and using Agile and Lean, one can give answer's to the other side which is how to do it and how to organize processes and iterations for realizing the project in less time, with less budget and under minimal risk.

\section{REFERENCES}

[1] Kronenberg. E., Majdalani. F, Arsenieva E., and Latka. J., Managing the Managers Effective PMC Oversight on Large Infrastructure Projects, Booz \& Company, www.booz.com.

[2] Esty B., C., Why Study Large Projects? An Intro-duction to Research on Project Finance, European Financial Management, Vol. 10, N0. 2, pp. 213-224, 2004.

[3] http://www.pmi.org/en/PMBOK/

[4] Royce, Winston, Managing the Development of Large Software Systems, Proceedings of IEEE WESCON 26 (August), pp. 1 - 9, 1970.

[5] IEEE Guide--Adoption of the Project Management Institute $(\mathrm{PMI}(\mathrm{R}))$ Standard, A Guide to the Project Management Body of Knowledge (PMBOK(R) Guide)--Fourth Edition IEEE Std 1490-2011, pp. 1 - 508, 2011.

[6] Beck, K, Extreme Programming Explained. Addison Wesley, Reading, MA, SCRUM, Schwaber and Beedle, 2002.

[7] http://www.dsdm.org

[8] Cockburn, A., Agile Software Development. Reading, Massachusetts: Addison Wesley Longman, 2001.

[9] Palmer, SR., Felsing, JM., A Practical Guide to Feature Driven Development Prentice Hall, 2002.

[10] Charette, R. N., www.itmpi.org/assets/base/images/itmpi privaterooms/robertcharette/ChallengingtheFundamentalNot ions.pdf.

[11] Highsmith, J., Agile Software Development Ecosystems, Addison-Wesley. 2002

[12] Zhang D. Z., Towards theory building in agile manufacturing strategies-Case studies of an agility taxonomy, Int. J. Production Economics 131, pp. 303-312, 2011.

[13] Wedgwood, I. D., Lean Sigma: A Practitioner's Guide, Prentice Hall, 2007.

[14] Beck, K., et al. (2001), Principles behind the Agile Manifesto, Agile Alliance, Archived from the original on 14 June 2010.

[15] http://jroller.com/bokmann/entry/.

[16] Datta., S., Agility measurement index: a metric for the crossroads of software development methodologies, Proceedings of the 44th annual Southeast regional conference, Pages 271 - 273, ACM New York, NY, USA, 2006.

[17] Lappo P., Henry C.T. Andrew. "Assessing Agility", http://www.smr.co.uk/presentations/measure. pdf, Retrieved 6 June 2010.

[18] Tisni K., Agility Metrics: A Quantitative Fuzzy Based Approach for Measuring Agility of a Soft-ware Process, ISAM-Proc. of International Conference on Agile Manufacturing, Norfolk, U.S, 2006. 
[19] Little., J. (2 December 2007). "Nokia test, A scrum-specific test". Agileconsortium.blogspot.com.

[20] Seuffert M., Karlskrona test, A generic agile adoption test, Piratson Technologies, Sweden, 2009

[21] Woods D., Why Lean And Agile Go Together, http://www.forbes.com/2010/01/11/software-leanmanufacturing-technology-cio-network-agile.html.

[22] Rosenau M. D., and Gitens, G. D., Successful Project Management: A Step-by-Step Approach with Practical Examples, Fourth Edition, Wiley, 2005.

[23] www.allaboutagile.com.

[24] Schwaber, K. Agile Project Management with Scrum, Microsoft Press, spemarti.googlecode.com /files/Schwaber2004.pdf

[25] http://www.sprintplanning.com/.

[26] Drickhamer, David, The Kanban E-volution, Material Handling Management, pp. 24-26., 2005.
[27] Ohno, Taiichi , Toyota Production System - beyond largescale production. Productivity Press. 1988.

[28] Hibbs, C., S. Jewett and M. Sullivan, The Art of Lean Software Development: A Practical and

[29] Incremental Approach, 1st edition, O'Reilly Media, Inc., CA, 2009.

[30] Poppendieck, M. and T. Poppendieck, Lean Software Development: An Agile Toolkit, Addison-Wesley Professional, 2003.

[31] Smits, H., The Impact of Scaling on Planning Activities in an Agile Software Development Center, In the Proceedings of the 40th Hawaii International Conference on System Sciences, Waikoloa, Big Island, Hawaii, 3-6 January 2007.

[32] George M., Combining Six Sigma Quality with Lean Production Speed, McGraw Hill electronic book text, ISBN 0071385215 / 9780071385213. 